\title{
Education, time-poverty and well-being
}

John White

UCL Institute of Education

\begin{abstract}
The paper focuses on 'objective list' accounts of personal well-being and the related view that schools should aim at inducting students into a wide range of objective goods. It reviews various objective lists, notes that very many of them include knowledge, a love of beauty and close personal relationships. It then seeks to explain why this might be so and cautions against narrowness in specifying intrinsic goods, before exploring the role of extensive personal time in engaging in them. The paper links all this to the current UK government's advocacy of knowledge and other cultural goods in English school aims, seeing this as an instance of a more global tendency. It argues that this approach both assumes a too restricted notion of intrinsic goods and - especially - is unrealistic in the light of wide-spread time-poverty. It suggests, finally, that if more personal time is to be sought, school reform must go hand-in-hand with wider social changes.
\end{abstract}

\section{Key words}

Well-being, objective goods, aims of education, time-poverty

I shall be assuming that it is one of the obligations of the state to protect and promote the welfare of its citizens. This applies to education policy as well as other areas like housing and security. In particular, the state - in some form, not necessarily in the shape of a minister of education - has a duty to lay down the broad aims of school education. It is reasonable to expect this, among other things, to benefit all students.

It can do this partly by focusing on basic goods like health, laying down aims (in this instance) in the area of health education. As well as basic goods those necessary for one's well-being - there are also the goods in themselves, those valued for their own sake, that constitute this well-being. What these goods are is disputed. For a hedonist, they are all forms of pleasurable experience. Others take them to be the objects of preference satisfaction, given an informed understanding of available options. For yet others, the constituents of well-being are not dependent on one's desires in this way, but objective rather than subjective. Lists of objective goods typically include such things as intimate personal relationships, aesthetic experience of art and nature, and knowledge.

Like many others, I see problems in the subjective position. Nozick's (1974: 42-3) 'experience machine' makes hedonism problematic, given that someone with only thoughts and feelings associated with various activities, but not the activities themselves, can scarcely be said to be leading a flourishing life. ${ }^{1}$ 
The informed desire-satisfaction view has the perverse consequence that a person's well-being is enhanced if they get the life of retirement that they have always wanted, even though it is a disappointment. In any case, the fact that someone satisfies a want, even an informed one, is not enough to show that they are engaging in something of value. Rawls's (1971: 432) famous example of the man who wants above all to count blades of grass in a city park brings this out.

Considerations like these suggest some kind of objective view of wellbeing. I will explore this possibility shortly, but first need to keep in view its bearings for education. Suppose we find good reasons why engaging in the items mentioned - intimate relationships, aesthetic experience and pursuing knowledge - enhances one's well-being. (Nothing hangs on the examples. We could talk more abstractly about items A, B, C...). There is no good reason why everyone's welfare has to depend on engaging in all these pursuits. In a society like our own that values personal autonomy, it would be enough if people engaged in those that suited them.

This supports a familiar account of a school's aims. It should induct students into a wide range of objective goods and encourage them to follow up in later life those that attract them. It has, of course, other legitimate aims - civic or vocational, for instance, but here I focus only on the student's own good. Given this, it is clearly important to try to determine the (objective) constituents of personal well-being.

\section{Lists of objective goods}

What guidance comes from philosophers' accounts of objective goods? Here is an abbreviated survey:

*Mill (1861: ch 2): mental pleasures: 'pleasures of the intellect, of the feelings and imagination, and of the moral sentiments'

*Moore (1903: 188): enjoyment of beauty, personal affection

*Ross: virtue, intellectual and aesthetic activities, justice and (others') pleasure

*Peters (1966: ch.5): pursuit of truth/theoretical activities, with a question-mark over aesthetic ones not connected with this pursuit, like music.

*Finnis (1980: IV.2): life, knowledge, play, aesthetic experience, sociability (friendship), practical reasonableness, religion

*Parfit (1984: 499) : 'such things as moral goodness, rational activity, the development of one's abilities, having children and being a good parent, knowledge, and the awareness of true beauty'

* Griffin (1986: 67): accomplishment, autonomy, understanding, enjoyment, deep personal relations

*Raz (1986: chs 12, 14; 1994: 3): autonomy (in a modern society); wholeheartedness and success in the pursuit of all worthwhile activities and relationships (not specified in detail)

* Scanlon (1996: 117): certain forms of enjoyment, success in achieving worthwhile ends: 'such things as friendship, other personal relations, achievement of various forms of excellence, such as in art or science'.

*Nussbaum (2006: 76-8): functionings in the areas of: life, bodily health, bodily integrity; senses, imagination, thought; emotions, practical reason, affiliation, other species, play, control over one's environment - political, material.

*Hooker (2015: 15) 'pleasure, friendship, significant achievement, important knowledge, and autonomy, but not either the appreciation of beauty or the living of a morally good life.' 
There is not a hundred per cent overlap by any means, but certain items often recur, especially close personal relationships/friendship, knowledge/understanding, aesthetic activities, and pleasure/enjoyment. Pleasure is here one item in an array of possible objective goods, not the only good as in hedonism.

Success/accomplishment is also in several lists. Some include it as a separate item, explicitly or, I suspect, implicitly restricting it to activities that, unlike torture or ear-wiggling, are valuable. Raz sees well-being in general as involving successful engagement in worthwhile pursuits.

Practical rationality, too, occurs on lists more than once, as does virtue/moral goodness. Practical rationality is again, a pervasive and necessary feature of personal wellbeing: it is not a more bounded component like play or a love of beauty. Insofar as the above list is of intrinsically valuable goods, one might quibble that practical rationality is a necessary enabler of engagement in such goods rather than one such good in itself. But against this is the Aristotelian insight that the fact that a good - a courageous disposition, for instance - is enabling does not rule it out as also valuable in itself.

Assuming that 'moral goodness' is synonymous with 'virtue', there are well-known problems about seeing it as conducive to or a constituent feature of personal well-being. (Cannot a tyrant live a flourishing life?) On the other hand, if friendship and other cooperative goods are among a person's intrinsic wellbeing goods, it is hard to see how they can fail to bring moral goodness with them.

Can we adopt a Razian perspective not only on success, but also on pleasure/enjoyment? He requires that engagement in a worthwhile pursuit be 'wholehearted'. If this is partly to be understood hedonically, would pleasure have to yield its possible place as a separately itemised good? Or could one imagine wholehearted immersion of an agonized sort, as in caricatures of Wittgenstein? Contra Raz, can pleasures not connected with active engagement contribute to well-being - unexpectedly enjoying a delicious cooking smell, perhaps, when waking from a doze?

Raz unlike Griffin does not make autonomy a separate item on a list, but sees it as a value prized in a society like our own - where people are encouraged to choose how they are to live their lives - but not in tradition-directed communities.

Play occurs in two lists. If it covers physical activities like games, this is the only place where bodily pursuits are recognized as intrinsic goods. For the most part the writers go along with Mill in emphasizing 'mental' phenomena.

Nussbaum's list is one that mentions play. I find it somewhat hard, more generally, to pigeonhole her list with the others, since some of her functionings have more to do with necessary conditions of well-being (bodily health, for 
instance) than with intrinsically worthwhile goods. On the other hand, if we take her list as a whole, it presents a rounded picture of enabling and constitutive features of human well-being that mirrors much of what many of the other philosophers in the list probably have in mind.

\section{Why the overlap?}

There is considerable overlap in these accounts of objective goods. What if anything can explain this?

They are not 'objective' in having some kind of existence independent of preferences. I do not know what this might mean. Preference-satisfaction theorists may agree, but say that all the overlap shows is that these writers, unlike some other people, have informed desires for such things as the pursuit of knowledge and personal intimacy.

But the philosophers are not expressing their personal preferences. They are not like consumers in a market all broadly agreeing, and independently of each other, that what they would most like as a television set would be a large flat screen one.

There are two differences. First, for them what is important is what things are intrinsically good for people in general. Their focus is on values applicable to all, not what would satisfy themselves. Secondly, they are not deciding independently of each other like the TV buyers. It is significant that they exercised judgments about the nature of well-being from within a shared tradition of philosophical thought about the topic.

A reply might be that the TV buyers are no more acting independently than the philosophers. Flat screen sets are in vogue. Consumers are motivated by what they see others buying. They react not solely as individuals but as members of a wider, interconnected group.

This is a fair point, but merely underlines the kind of connectedness among the philosophers. Insofar as consumers are influenced by each other, this is because they are collectively the instruments of those who have produce to sell. The philosophers are no one's instruments. They are autonomous, independent thinkers, sharing their ideas so as to test out their soundness.

Their tendency towards convergence gives us some reason to think that such things as intimate relationships, aesthetic and intellectual pursuits, and possibly forms of play are among objectively good ends in societies like our own, given that people choose them autonomously and engage in them successfully and with enjoyment or wholeheartedness.

I stress 'some reason to think', bearing in mind that we have been dealing with very few philosophers, and that philosophers opposed to objective lists would disagree. The converging philosophers are also likely to have cultural interests in artistic and intellectual fields and their 'objective' lists may, perhaps 
unconsciously, be biased towards them. More practical activities, that for many people are sources of intrinsic delight as well as functional, like gardening or doit-yourself, are not among them.

\section{Well-being in historical perspective}

Let us pursue the convergence further. It is not just philosophers who value close relationships, art and learning. In White (2007), influenced by Raz (2003), I discussed the development of attachments to these and other well-being goods over the past three or four centuries, showing how an interest in the arts burgeoned across a proliferating number of genres and sub-genres - a tendency found among other intrinsically valuable goods. The result is that we are now living in a vastly more complex and differentiated world of well-being goods than our ancestors in the seventeenth century - a time when the novel, the main genres of music, all kinds of personal, family and collegial relationships, swathes of academic disciplines and sub-disciplines and countless intrinsically worthwhile forms of work were unknown. How closely this development is linked with the growing, and accelerating, belief over that period that human life is to be enjoyed for what it is and not as preliminary to eternal life, I do not know.

Accompanying this has been a growing higher-order interest in how one can tell what makes a pursuit intrinsically worthwhile, or more so than another. In the same article, I discussed J S Mill's well-known claim that mental pleasures are higher in value than physical ones because those acquainted with both markedly prefer the former. Whatever one says about its soundness, a condition of being taken seriously in debates about intrinsic valuable pursuits is that one has a broad acquaintance with candidates of many types. Those who know nothing about art, or sport, or the pursuit of knowledge or lying in the sun are not in a good position to make judgments about their place in a flourishing life.

Those who do have a wider involvement, I suggested, 'must be people who have some knowledge about all these things and who also must have some free time and freedom of spirit in which to do their thinking' (White 2007: 24). While three centuries ago these were found among the rich and their associates, there has been a huge enlargement from that narrow social basis: virtually all living today in a country like Britain have 'been exposed to a huge array of wellbeing goods, some experienced directly, others via the imagination'. A smaller, but still considerable number, 'thanks to educational improvements, engage in artistic, intellectual and other pleasures less accessible to others'.

I saw this historical development as some reason to doubt the subjective view of a person's well-being that defines it in terms of how far that person's informed preferences are met. For what has grown up is a large, if ragged-edged, group of people qualified to make judgments - some acquainted with a wider range of intrinsic goods than others - about the well-being not only of themselves but also of people generally. On this view, well-being judgments are still dependent on desires, but no longer, as on the subjective theory, on the agent's. We have instead the shared judgments of an amorphous group of 
people, with most weight given to the judgments of those with the most comprehensive experience of well-being candidates.

How far we can call these judgments 'objective' is moot. We are in the realm of long-term aspiration rather than a present reality. Judgments about well-being are more like those about the aesthetic merit of works of art than those to do with the soundness of a piece of historical writing, and even more so with judgments in the physical sciences. If we take the three fields in reverse order, the role of sensitivity to empirical or logical fact grows less, and that of individually-differing weighting of values - moral, aesthetic, personal - becomes larger.

Where values-weighting comes into the picture, the aspiration towards objectivity is on the way to being met as those judging become more aware of differing value-judgments among them, of their final irreconcilability in some cases, and of the extent to which judgments are based on arguments whose cogency those of other value persuasions can acknowledge. We see this in the aesthetic area, where, although there is continuing dispute over the value of many works of art, most critics have come to realize the good reasons behind judgments made from other value positions, as well as the openness of their own judgments to legitimate disagreement. All this suggests that progress towards greater objectivity in value-laden fields like art criticism is partly a function of increasing catholicity, in accepting as legitimate views with which one sometimes radically disagrees.

How does this relate to views about well-being? It offers some hope that the aspiration, mentioned above, towards greater objectivity can be met. Philosophers are in a favourable position here, since the aspiration depends on discussion of opposing views and this is the lifeblood of those working in universities. But it can also be a weakness if the debate remains inward-looking, slanted towards widely shared predilections for intellectual and other highcultural activities within this group. The more open the discussion to outside views, the more the value of catholicity is likely to be realized.

\section{Time and well-being}

Granting the desirability of this openness, their experience of the pursuit of understanding for its own sake that few others have privileges philosophers - on Mill's argument - in assessing well-being candidates. A condition of being able to assess these candidates is having the time to do so (see above). Philosophers have more of this than most people. In this they are, other duties apart, in a somewhat similar position to the more cultured members of earlier leisured classes. This is one reason why their views should be taken seriously - as should those of writers and others with time to contribute to public debate on these issues.

Time is necessary not only for thinking about well-being, but also, and in more abundance, for engaging in the more time-consuming of its possible components. Among these are the pursuit of understanding and of artistic ends, 
in both creation and enjoyment. Philosophers are appointed to universities with the time for the former, and their interests often extend to the arts. Given their type of profession, authors, artists and journalists outside academia also have more time than most to explore these cultural pursuits.

Close personal relationships also take time to create and depend on time to be enjoyed. Most people, including most philosophers and writers, have experience of these, even though fewer people have the experience of intellectual and aesthetic pursuits that puts academics and writers in a more favourable position to comprehensively assess well-being candidates.

In mentioning time in the above paragraphs, I have in mind fairly long stretches of it. Instances of any candidate component of well-being must, of course, take place in time. This is true of eating an ice-cream, listening to an album, or even of catching the scent of roses as one walks past them. But it is noteworthy that the three items that recur most often on philosophers' lists are the pursuit of knowledge, aesthetic activities and close personal relationships, all of which need longish periods of time.

This is significant if we take well-being across a lifetime. In Britain and other countries we live on average eighty years or longer. In a life rich in wellbeing much of that time, infancy and illness excepted, is likely to be spent on intrinsically worthwhile pursuits - granting that much, too, is needed for purely instrumental activities ('purely instrumental' excludes activities with both instrumental and intrinsic aspects, like being a teacher, perhaps).

If you are absorbed for long periods in worthwhile pursuits requiring extended engagement, you are well placed to lead a life of great fulfilment. Griffiths (1965) throws light on this. For him the essence of the university lies in engagement in certain intrinsically valuable activities - the pursuit of learning in various academic disciplines. I do not agree with him that the university has an essence that makes it unique: it is an administrative category at the top of a hierarchy of post-school institutions, and, in the British context, not sharply differentiated in its aims from a further education college (White 2009). But what he writes about activities valuable in themselves is helpful. An early exponent of a point more fully developed by advocates of achievement motivation and 'flow', he suggests that the object of such an activity contains a feature he calls 'reciprocity' (1965: 190). 'In acting on it, it bounces back again and one may miss it or it may bump one in the nose; or it may return from an unexpected angle which presents itself as a discovery demanding a new response'. His claim is that 'activities are more valuable as these modifications (of consciousness) are richer and capable of indefinite development without mere repetition'. Whether he is right about a scale of value, I do not know. But one of the characteristics of academic pursuits is an apparent inexhaustibility of features that absorb your attention and make you want to explore further. This is why, in a long lifetime in which you have plenty of time to yourself, academic pursuits can be excellent vehicles of well-being. 
Griffiths's focus is academic activities, but his notion of 'reciprocity' also applies to the two other favourites on philosophers' lists, aesthetic pursuits and close relationships. It applies to both the creation and enjoyment of works of art as well as to aesthetic appreciation of nature. Being with one's long-time partner, an old friend, or a family member can lead to myriad, and often tiny, new perspectives of all kinds, on relationships, common interests, a shared past.

Other activities pursued for intrinsic reasons can also be endlessly absorbing: playing or watching sports, chess and other non-physical games, gardening, craft activities, teaching...

\section{Educational aims}

I argued earlier that schools' aims should include equipping students to enjoy self-chosen worthwhile activities throughout their lives. Current official statements of school aims in England and Wales are in line with this. In $2014 \mathrm{a}$ new overall aim for the National Curriculum appeared (DfE 2014 3.1):

The national curriculum provides pupils with an introduction to the essential knowledge they need to be educated citizens. It introduces pupils to the best that has been thought and said, and helps engender an appreciation of human creativity and achievement.

The reference to 'the best that has been thought and said', quoted from Matthew Arnold (1875: x), bears the hallmark of Michael Gove, then the Secretary of State for Education. He is also an advocate of personal autonomy, saying of teachers in 2013 that they 'give children the tools by which they can become the author of their own life story and builders of a better world'. ${ }^{2}$

The Arnoldian theme continued into the Conservative government elected in 2015. Nick Gibb, the Schools Minister, said in July of that year that 'education is the engine of our economy, it is the foundation of our culture, and it's an essential preparation for adult life'. ${ }^{3}$ The second of these is about 'introducing (the next generation) to the best that has been thought and said, and instilling in them a love of knowledge and culture for their own sake'. In his speech he said that schools must teach pupils the 'fundamental principles' of core subjects in a way that will enable them to read around the subject for leisure as adults. ${ }^{4}$ 'That's the purpose of education in my judgement, in every subject. Can you read a geography book after you leave school, can you read further history books by famous historians after you leave school? The purpose of school is to provide that grounding to indulge and read around those subjects as you go through adult life.'

British government interest in 'cultural' aims raises a number of issues of more global relevance:

[1] The idea of people pursuing academic activities in their leisure time, if they want to, is fine. Curling up with a geography book would not be my own choice, but the notion of everyone having the leisure to pursue worthwhile activities of all sorts is appealing. Policy-makers should avoid making the spectrum of their 
intrinsically valuable pursuits too narrow. Gove and Gibb seem to confine these mainly to forms of knowledge as well as literature. But our earlier discussion of objective lists spoke in favour of a more catholic stance. Most philosophers also included close personal relationships and some would extend the list to such things as play and a love of beauty in art and perhaps in nature. The earlier argument also suggested extending the range to include practical activities like gardening, craft activities and teaching.

Some may object that many of these additions are not academic enough for a school's programme. But this assumes that schools should only be concerned with academic matters. If the educational aim under discussion is to equip students to engage in intrinsically valuable pursuits throughout their life, there is no reason to trim these back to the preferences of an Arnold devotee.

Close personal relationships may still present a problem: surely schools should not be inducting students into intimate friendships and erotic relationships as part of their mission? Maybe. But something rather less than this is well within in their province: welcoming the friendships that students form, both in themselves and as ingredients of curricular activities. In addition, schools can open young people's eyes to the contribution friendships and erotic relationships can make to people's well-being. Students can explore this not only via reading literature, but also through discussion, film, documentary material and other approaches familiar in good sex-and-relationships education.

There is a strong case, therefore, for catholicity. A narrow focus on academic goods alone can be harmful. Students eager to learn tend to trust their teachers as people who know what is good for them and are leading them in a beneficent direction. They are let down if these teachers, following higher authority, are blinkered in their vision.

[2] The second issue is about how schools engage students in intrinsically valuable pursuits. In England and Wales this is linked to high stakes examinations. The British government steers schools towards its preferred subjects by making their league table positions dependent on results at the GCSE exam for sixteen year olds, with its new English Baccalaureate benchmark of five good passes in English, maths, science, a foreign language and either history or geography. This associates the pursuit of knowledge dangerously closely with exam success. Given that the aim in question has a child's whole future in mind, schools should be developing a love of history, science, etc. for their own sakes, encouraging students to explore new avenues and reach deeper layers of understanding. This is not incompatible with preparing for examinations, but pressures on schools for their students to do well in them, as well as pressures on exam boards to make their marking as objective as possible in the interests of fairness, work in an opposite direction.

The objectivity requirement privileges items high on inter-examiner reliability like those asking for factual knowledge. The more an item depends on interpretation or value-judgments - like a deeper understanding of historical facts, or critical judgment about a work of literature - the more markers are likely to disagree. Teachers are also often tempted, in the interests of their students, to 'teach to the test'. Preparing for an examination is always stressful, 
especially in high-stakes testing. It is hard to see how intensifying students' anxiety about this and its instrumental consequences is compatible with deepening a wholehearted absorption in pursuing knowledge for its own sake.

If love of an activity is what is wanted, there is every reason for detaching it from high stakes examinations and thinking more carefully about better ways of promoting it.

\section{School education, social reform and personal time}

[3] A third and more central issue for this paper arising from current policy in England and Wales has to do with personal time. We have seen that Gibb's main aim, following Gove, is about 'introducing (the next generation) to the best that has been thought and said, and instilling in them a love of knowledge and culture for their own sake'. This has implications for students' use of time both at school and throughout adult life. We have seen that absorption in such things as history, science or literature is time-consuming. At school, time for developing a genuine love of such activities is limited by the utilitarian demands of examinations, as well as interruptions by the bell. Postschool, prospects for most people are often slim. Some will be drawn towards occupations like university or school teaching, or work in the arts and in the media, hoping to spread their intellectual or artistic wings in their job; others, towards work in the City that will give them financial independence by thirty. Those who succeed may attain the Gove-Gibb ideal, but not all by any means will succeed; and those who go for employment rather than independence may be disheartened by its routine demands on them.

This leaves the great bulk of the population below retiring age in jobs that have little or space for intellectual and artistic pursuits, or without a job at all. Among these, those who are bringing up children tend to be especially short of time. If paid employment took only a few hours a week, those in work would be able to follow their cultural pursuits in their ample free time. But this is far from the case, especially in the UK, where people spend longer in full-time work than in most European countries. ${ }^{5}$ This applies not only to those in the least sought after jobs, since executives sometimes work longer hours than they need to so as to better their chances of promotion. But at least their work is usually interesting. It is harder for the millions in lower-paid, often more tiring, typically more boring jobs whose hours of work, including overtime, are longest of all.

When education ministers enthuse over the intrinsic delights of reading a history book or a good novel in one's free time as a rationale for their Arnoldian curriculum, I wonder whether they have taken the brute reality of most people's daily lives into account. Their standpoint is more reminiscent of one of the zaniest of the Monty Python sketches, where several Welsh coal miners deep underground are at it hammer and tongs about eighteenth century history and Greek classical architecture. ${ }^{6}$

The ministers' stance assumes, in any case, that schools will be successful in instilling a love of science or literature in every pupil. But again the reality is different. Even many of those who do well in our examination culture are only too glad once their papers are over to leave forever the maths or foreign languages on which they have worked so hard and for which they may well earn 
high marks. As for those with poor exam results, it is even more unlikely that they will find joy in higher culture.

The discussion so far in [3] has been confined to the intellectual/cultural goods that education ministers have made central. As I have suggested more than once, there is a case for adopting a more inclusive perspective on intrinsic goods. But adding in close personal relationships and things like gardening, playing games or walking in the country only exacerbates the problem. All these pursuits depend on having ample time at one's disposal; and it is this, in our time-poor world, that so many people lack.

What might be a way forward? Let us first review the kinds of intrinsic pursuits available to those from all social strata who are too time-poor and in very many cases too lacking in prerequisite attainments to engage in the cultural pursuits our ministers prize. Some people have, indeed, no time to themselves at all. These aside, many others spend much of their sparse leisure in interactions with close friends and family. These could well occupy them for longer stretches, if they had the time. Then there are pleasurable experiences that are in themselves lower in reciprocity. Familiar examples include watching sport and other TV shows, listening to music of the day, going for a drink, eating fast food, keeping in touch with social media, looking through magazines, tabloids and internet material, going round the shops. Activities like these are packaged in small units and suit those with little free time; they are undemanding and it is easy to finish with one and pass on to another.

All of these can be, and perhaps usually are, shared social activities. Insofar as they are, this reinforces the salience of relationships in the private lives of the time-poor. These may be for some people the only item available to them from the philosophers' lists of intrinsic goods.

I am aware that these things come increasingly into the mix of enjoyable pursuits that most of us now engage in. To draw on recent work on cultural capital by the sociologist Mike Savage (2015: p.112), the kinds of 'highbrow' activities such as are found in the philosophers' lists are now predominantly the preserve of older, middle-class, British people. Younger ones from the same social group are more eclectic, even if their approach to popular music, social media and other such activities tends to have a 'knowingness' (p.114), a discernment, becoming perhaps a new form of snobbery, that distinguishes them from those less well educated, for whom popular culture is seen 'as a kind of escapism which [allows] you 'time out'.' (p.119).

Insofar as we can abstract relationships values from these forms of popular culture, in themselves they may or may not be intrinsically valuable. They can be defended as making people's lives more fulfilling not only on a hedonist theory, but also on an informed desire-satisfaction view of well-being. Channels of information of all sorts can give people a good idea, often in microdetail, of the various options open to them. They are free and encouraged to choose among all these pleasures. On the other hand, the more the scene is being managed for them by salespeople and their adjutants, the less they are autonomous shapers of their preferences. If informed desire-satisfaction is not adequate as criterion of well-being, and we are looking for other features as 
described above, many of these unhighbrow pursuits - their links with social interaction bracketed off - may come out low on as ingredients of personal flourishing.

This is all the more true the more they are pursued for extrinsic rather than intrinsic reasons. These may be present in the outlook of the discerning middle-class consumers of popular culture mentioned above, insofar as their involvement is driven by a snobbish desire to be seen as above the common ruck. Those who go in for the popular activities for escapist reasons, or to keep up with the crowd, are also to that extent extrinsically motivated - always bearing in mind that all these things are also chosen for their pleasurableness. The same is true of those from all parts of society whose use of digital technology, including smart phones and social media is partly driven by an egocentric desire to be noticed and approved by others.

I do not necessarily wish to deny all intrinsic value to the popular culture I have been describing. Its hedonic aspects may well make it better than a slave's life of unremitting toil. But if people across society had more time to themselves and a different kind of education focused less on exam success and more on wholehearted and intrinsically directed engagement in a wide range of activities, not just academic ones, many lives - including those in which popular activities figured along with others - might be far more fulfilling.

It is not enough to think of educational reforms on their own. However rich the school's provision becomes for a life of personal well-being, opportunities for a flourishing life will be slim if most people work the hours they do now. Here as elsewhere, educational reform has to be premised on reforms in the wider society.

John Maynard Keynes (1930) envisaged a world in a hundred years time in which people had to work no more than about twelve or fifteen hours a week. Around the same time, Bertrand Russell (1935: ch.1) argued for limiting work to a compulsory four-hour day. Both were writing in the tradition of earlier social reformers pressing for on-going reductions in the working week. This way of thinking, which remained mainstream in progressive British circles until after the second world war, has now given way for decades to resigned acceptance of a long-hours culture.

This is advantageous to employers, but not, for the most part, to employees. This paper is not the place to examine alternatives that give the latter more time. For one thing, this would open up large issues about whether economic growth should remain a political priority or give way to a vision of a society with less emphasis on production and consumption and more on a better life for all.

School reform would thus have to take place pari passu with wider social changes. The aim of equipping all students for a flourishing life would find its place within a wider scheme, including also civic, vocational and moral objectives. If it is to be properly pursued, sensible means of doing so need to be in place. This would mean rejecting the current stranglehold that tests and exams have over the school curriculum. It would mean, among other things, 
introducing students to a catholic array of intrinsic goods among which they will be able to make autonomous choices throughout their lives.

Some indication of how this might work is to be found in Reiss and White (2013). But the ideas in that book will have to stay pipe dreams unless harnessed to wider notions of social reform that free people up to lead lives more of their own. The prospects for realising these seem poor if Thomas Piketty (2014, chs. 11,12 ) is right in his claim that the post-war movement towards greater equality in countries like the UK and France has now gone into reverse and that we are reverting to the social structures of the late nineteenth century. But is this too pessimistic?

\section{Notes}

${ }^{1}$ For a defence of hedonism in face of the 'experience machine' problem, see Crisp (2006, pp 117-125).

${ }^{2}$ https://www.gov.uk/government/speeches/michael-gove-speaks-about-theimportance-of-teaching

${ }^{3}$ https://www.gov.uk/government/speeches/the-purpose-of-education

${ }^{4}$ https://www.tes.co.uk/news/school-news/breaking-news/schools-ministerpurpose-education-understand-academic-texts-and

${ }^{5}$ http://www.theguardian.com/news/datablog/2011/dec/08/europe-working$\underline{\text { hours }}$

${ }^{6}$ https://www.youtube.com/watch?v=yDmmeJOGKXY

\section{References}

Arnold, M. (1875) Culture and Anarchy (Second edition) London: Smith, Elder and Co.

Crisp, R. (2006) Reasons and the Good Oxford: Clarendon Press

DfE (2014) National Curriculum for England: framework for key stages 1-4 London: Department for Education https://www.gov.uk/government/publications/national-curriculum-in-englandframework-for-key-stages-1-to-4/the-national-curriculum-in-england-framework-for-keystages-1-to-4

Finnis, J. (1980) Natural Law and Natural Rights Oxford: Oxford University Press

Griffin, J. (1986) Well-being Oxford: Oxford University Press

Griffiths, A. P. (1965) 'A deduction of universities' in Archambault, R.D. (ed) Philosophical Analysis and Education London: Routledge and Kegan Paul

Hooker, B. (2015) 'The elements of well-being' Journal of Practical Ethics 3: 1 
Keynes, J.M. (1930) 'Economic possibilities for our grandchildren’ Essays in Persuasion, New York: W. W. Norton \& Co., 1963, pp. 358-373.

https://www.marxists.org/reference/subject/economics/keynes/1930/our-grandchildren.htm

Mill, J.S. (1861): Utilitarianism in Utilitarianism, Liberty, Representative Government (1910 edition) London: Everyman

Moore, G.E. (1903) Principia Ethica Cambridge: Cambridge University Press

Nozick, R. (1974) Anarchy, State and Utopia Oxford: Blackwell

Nussbaum, M. (2006) Frontiers of Justice Cambridge, Mass.: Harvard University Press

Parfit, D. (1984) Reasons and Persons Oxford: Clarendon Press

Peters, R.S. (1966) Ethics and Education London: Allen and Unwin

Piketty, T. (2014) Capital in the Twenty-First Century Cambridge, Mass.: Harvard University Press

Raz, J. (1986) The Morality of Freedom Oxford: Clarendon Press

----- (1994) Ethics in the Public Domain Oxford: Clarendon Press

---- (2003) The Practice of Value Oxford: Clarendon Press

Reiss, M. and White, J. (2013) An Aims-based Curriculum: the significance of human flourishing for schools London: Institute of Education Press

Russell, B. (1935) In Praise of Idleness London: Allen and Unwin

Savage, M. (2015) Social Class in the 21 ${ }^{\text {st }}$ Century London: Pelican Books

Scanlon, T. (1996) 'The Status of Wellbeing' Tanner Lectures on Human Values 16 Michigan Quarterly Review XXXVI (1997), pp. 290-310. http://tannerlectures.utah.edu/ documents/a-toz/s/Scanlon98.pdf

White, J. (2007) 'Wellbeing and education: issues of culture and authority' Journal of Philosophy of Education Vol 41 No 1

(2009) 'Further and Higher: a philosophical divide?' in Garrod, N. and Macfarlane, B. (eds) Challenging Boundaries: managing the integration of post-secondary education London: Routledge 